\title{
Effect of partial solar eclipse on the behaviour of solar cell parameters
}

\author{
Ahmed El-Sayed Ghitas \\ Solar Physics Laboratory, National Research Institute of Astronomy and Geophysics, Helwan, \\ Cairo, Egypt. \\ email: Aghitas@hotmail.com
}

\begin{abstract}
The performance of the solar cell is influenced by the spectral solar distribution. The silicon solar cell spectral response does not totally coincide with the solar spectrum. In the case of sun light exposure at outdoor conditions, the shapes of the cell spectral response curves are slightly different than that of under simulated light exposure. This paper is interested in studying the effect of variation of solar radiation during the partial eclipse on the output short circuit current and open circuit voltage of the monocrystalline and amorphous silicon solar cells. Also, the spectral cell behaveiour in terms of the solar eclipse was investigated. The ultimate goal is to explain some of an interesting natural phenomenon by using the solar cell spectral response.
\end{abstract}

Keywords. Solar eclipse, Silicon Solar cells, Temporal spectral scale

\section{Introduction}

Partial and total solar eclipses have been the exclusive concern of Astronomy and Astrophysics. However over the decades of this century these phenomena have been taken seriously into account by the Atmospheric and Environmental Sciences to study the response of the atmosphere during the interesting and particular circumstance in which solar light is partially or totally being blocked by the Moon. A total eclipse of Sun is about as close to a controlled experiment as an atmospheric research can hope for. Sunlight diminishes at a uniform and predictable rate, and near totality, the dark umbra of the Moon sweeps across the top of the atmosphere in a narrow predictable path. It is then possible to study how chemical (ozone layer changes, see Chudzyski, Czyewski, et al. (2001)) and physical processes in the atmosphere take place owing to the absence of sunlight. However, the effects most important for the environment take place in the microscale and involve changes of the boundary layer parameters of physical (thermodynamic processes) and chemical nature as plants response for light level decrease which causes decrease of $\mathrm{CO}_{2}$ flux, etc. Fabian, Rappenglück, Stohl, et al (2001 ).

Eclipses are connected with the rapid and short-time, impulse-like decrease of solar energy flux reaching the area of its visibility. Therefore, they cause noticeable changes in the atmosphere, whose main energy source is solar radiation. The strongest effects concern the layers where solar UV radiation contributes to ionization process (ionosphere) and the boundary layer which is in direct contact with the ground absorbing shortwave radiation. Especially, the impact on air temperature can be important, as the stability and convective processes intensity change Szalowski (2002). Some of researches are interested by the spectral distributions of skylight during the period of partial solar eclipse. The total radiation, the colour coordinates from the spectral distributions and the ratio $\mathrm{I}_{600} / \mathrm{I}_{520}$ as a measure of the change in the spectral distribution are discussed in relation to the results obtained by others Sastri (1968). 

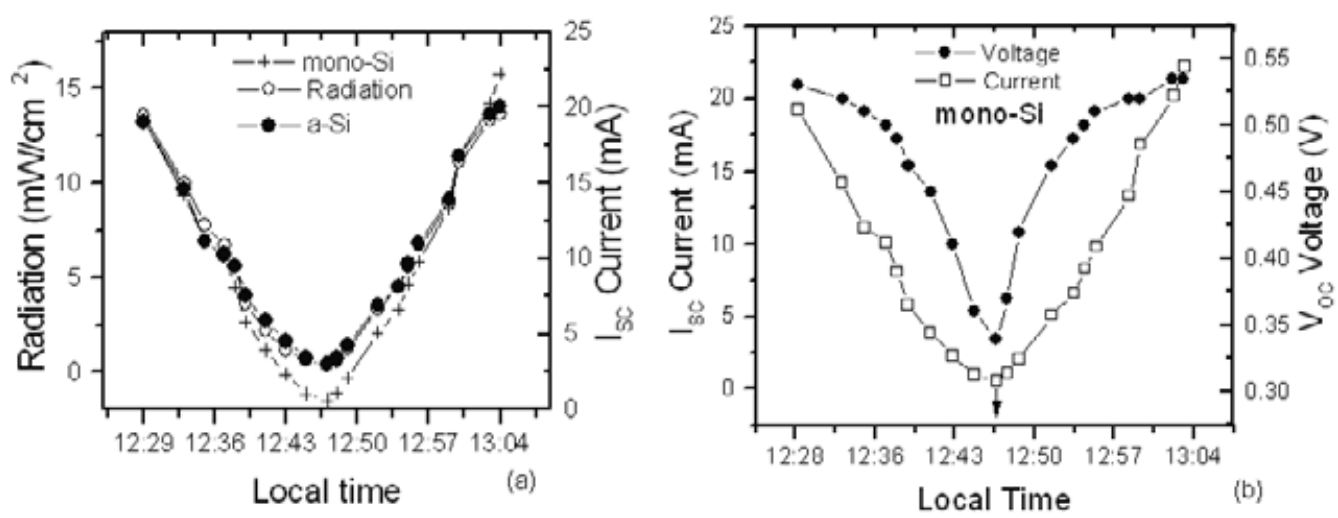

Figure 1. The variation of solar radiation with the current of mono-Si and a-Si solar cells sensors during the partial eclipse (a), and the phase change of voltage-current of mono-Si cell during the short period of that eclipse (b).

illustrated in figure 1(a). The figure shows specific identical diminishing occurring for the $\mathrm{I}_{S C}$ cell sensors owing to the depression of radiation in the period $35 \mathrm{~min}$ of the two wings, except small noticeable variation in the left wing very near to $t_{\max }$ apprehended by spectral effect. On the other hand, the circumstance status of the phase change of open circuit voltage and short circuit current of mono-Si cell sensor during the short period of partial eclipse represent a different in the depression bands as shown in figure 1(b). The $\mathrm{V}_{O C}$ reveals a sharp depression rather than $\mathrm{I}_{S C}$ which represent a broadening line curve. The reason is obvious, where the voltage is logarithmic related to the current. Accordingly, the observations made in this work are based on a variation of the solar cell performance, specifically the photovoltaic current output of the cell. The cell current is more sensitive to the ambient conditions than the cell voltage. To apprehend the spectral influence of solar eclipse on output current of the silicon solar cells, one should recognize firstly the spectral cell response. The relative spectral response of amorphous silicon solar cell is shown in Fig. 2(a). The curve represent maximum response in visible region at wavelength $550 \mathrm{~nm}$, and very low response in the red and IR wing. From $800 \mathrm{~nm}$ the a-Si appears zero response see Ghitas (2000). This main that, the cell has high sensitivity to the incident solar radiation in the visible band of range $380-700 \mathrm{~nm}$.

Once the spectral response $\mathrm{SR}$ is known, the total photocurrent density $\mathrm{J}_{L}$ obtained from the solar spectral distribution $\mathrm{F}(\lambda)$ is given by:

$$
\mathrm{J}_{L}=\mathrm{q} \int_{0}^{\lambda m} \mathrm{~F}(\lambda)[1-\mathrm{R}(\lambda)] \operatorname{SR}(\lambda) \mathrm{d} \lambda
$$

where $\lambda_{m}$ is the longest wavelength corresponding to the semiconductor band gap, $\mathrm{F}(\lambda)$ the number of incident photons / $\mathrm{cm} 2$ /sec per unit band width, and $\mathrm{R}(\lambda)$ the fraction of these photons reflected from the surface. To obtain large $\mathrm{J}_{L}$, one should minimize $\mathrm{R}(\lambda)$ and maximize $\operatorname{SR}(\lambda)$ over the wavelength range $0 ; \lambda ; \lambda_{m}$ Sze (1981).

Figure 2(b) shows the measured spectral response of the monocrystalline silicon cell sensor. It has broad wave band over the range $400 \mathrm{~nm}$ to $1000 \mathrm{~nm}$, and the maximum peak response lies at wavelength $825 \mathrm{~nm}$ in the near IR band. The intensity for each response curve are taken in arbitrary unit (a.u.) for shape comparing with the light source spectrum, and the absolute values are considered for the solar cell performance.

The only one sharp peak of the relative change of open circuit voltage for the two sensors (monocrystalline and amorphous silicon cells) are obviously in figure 3(a). The 

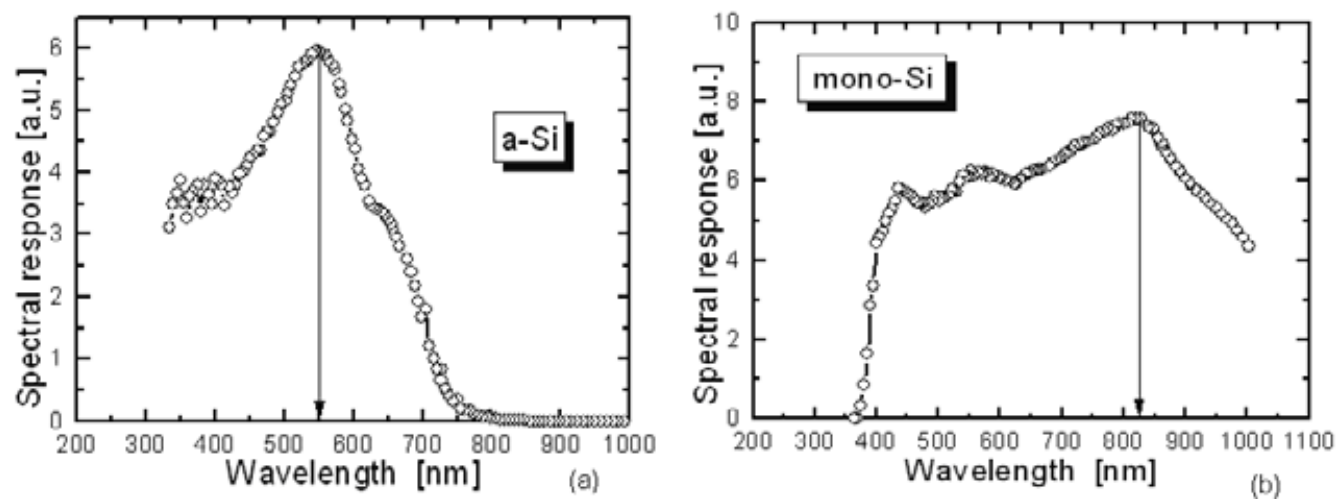

Figure 2. The spectral response of the amorphous silicon cell sensor (a), and monocrystalline silicon cell sensor (b).
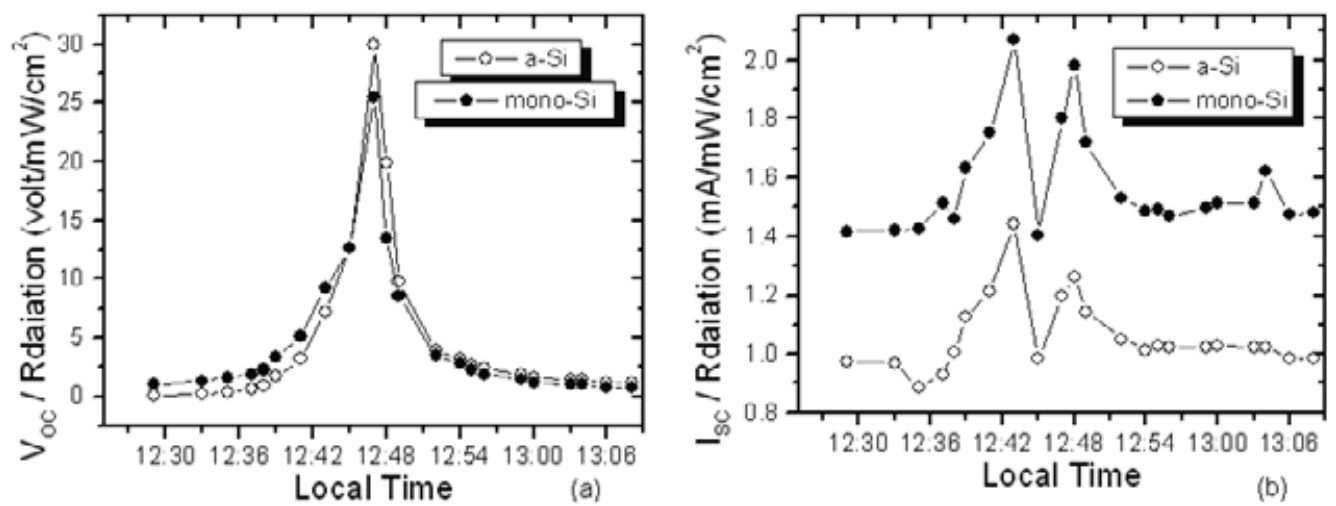

Figure 3. The relative change of output voltage of a-Si and mono-Si cell sensors (a) and output current $(\mathrm{b})$ per incident radiation around $\mathrm{t}_{\max }$ of eclipse.

peak represent a uniform reflection of the two line wings around $t_{\max }$ with inversely path of line curves. There is a noticeable continuous increase of monocrystalline line curve in the left wing of $t_{\max }$ greater than the amorphous line curve owing to eclipse sunset, where the cell is highly sensitive as mentioned in figure $2(\mathrm{~b})$. In the right wing with eclipse sunrise a-Si reveals enhancement of the line curve than mono-Si may be due to the absence of the abundance of scattering light at the rising. Figure 3(b) represent the relation of output short circuit current of a-Si and mono-Si solar cell sensors per incident radiation during 40 minute around the maximum of eclipse $t_{\max }$. The eclipse has the advantage over sunset of occurring very rapidly, and with the Sun hardly moving in the sky. Accordingly, sunlight diminishes at a uniform and predictable rate, and near maximum eclipse there is a chemical and physical processes change in the atmosphere take place owing to the absence of sunlight.

It is seems from the figure that, pre $t_{\max }$ look likes beginning of sunset with high scattering of radiation in red and infrared band, therefore monocrstalline silicon cell curve reveals peak in the left wing, which correspond to the maximum spectral sensitivity of this cell in this band. In contrarily, the amorphous silicon cell curve line demonstrates dropping in the left wing (pre $t_{\max }$ ) owing to depthless spectral sensitivity of this cell in that band as mentioned before. 


\section{Conclusion}

Our measurements data from the partial solar eclipse of 11 August 1999 have yielded an significant variable electrical cell parameters, which explain spectral prediction of many observers at solar eclipses and several have been put forward. The ultimate goal is to explain fully an interesting natural phenomenon. This will not only be satisfying in itself, but might also increase understanding of other phenomena that depend on atmospheric scintillation, such as the 'seeing' in ground based astronomical telescopes. Though lack of measured fast local spectral response of the monocrystalline and amorphous silicon solar cells during this eclipse to which laboratory measurements and observations can be compared.

\section{References}

Chudzyski, S., Czyewski, A., Ernst, K., Pietruczuk, A., Skubiszak, W., Stacewicz, T., Stelmaszczyk, K., Szymaski, A., Sówka, I., Zwodziak, A., \& Zwodziak, J. 2001, Atmospheric Res., 57, 43-49.

Fabian, P., Rappenglück, B., Stohl, A., Werner, H., Winterhalter, M., Schlager, M., Stock, P., Berresheim, H., Kaminski, U., Koepke, P., Reuder, J., \& Birmili, W. 2001, Meteorologische Zeitschrift, 10, No. 3, 187-192.

Karol Szalowski, 2002, J. Atmospheric and Solar-Terrestrial Phys., 64, 1589-1600.

Sastri V.D.P. 1968, Planetary and Space Science, 16, No. 5, 647-651.

Sze S.M. 1981, Physics of Semiconductor Devices, 2nd Edition, John Wiley and Sons, Inc., New York.

Ahmed Ghitas, 2000, PhD thesis, University of technology, Bratislava, SK. 